Running head: Imagined contact and collective action

When imagining intergroup contact mobilizes collective action: The perspective of disadvantaged and advantaged groups 


\begin{abstract}
The current studies aimed to reveal the potential role of imagined intergroup contact on collective action tendencies within a context of intergroup conflict. Study 1 (disadvantaged Kurds, $N=80$ ) showed that imagined contact increased collective action tendencies and this effect was mediated by increased perceived discrimination and ethnic identification. Study 2 (advantaged Turks, $N=127$ ) demonstrated that imagined contact also directly increased collective action tendencies, as well as perceived discrimination and relative deprivation among the advantaged group. No significant mediation emerged. At the same time, in line with literature, imagined contact led only the advantaged group members to display more positive outgroup attitudes. Findings suggest that in settings where ingroup identities and conflict are salient, imagined contact may not readily undermine motivation for social change among group members.
\end{abstract}

Keywords: Imagined contact; collective action; discrimination; attitudes; identification; conflict 


\section{When imagining intergroup contact mobilizes collective action: The perspective of disadvantaged and advantaged group members}

Social psychology literature provides substantial evidence for the success of intergroup contact in reducing prejudice and discrimination in various intergroup contexts (Pettigrew, 1998; Pettigrew \& Tropp, 2006). Recently, there has been increased attention on the investigation of other -unintended- consequences of intergroup contact at the societal level and researchers have started to explore whether intergroup contact possibly deters group members from collective action in support of their ingroup's rights. This emerging literature indicates that although intergroup contact provides benefits as regards intergroup harmony by promoting positive intergroup relationships, it may simultaneously discourage social change that is fundamental for societies (e.g., Dixon, Tropp, Durrheim, \& Tredoux, 2010; Wright \& Lubensky, 2009). Hence, although both intergroup contact and collective action theories provide a framework for the progress of societies, they seem to emphasize distinct routes to achieve intergroup equality. We aimed to extend this line of research by examining the role of an indirect form of intergroup contact, imagined intergroup contact (Turner, Crisp, \& Lambert, 2007), on collective action tendencies among disadvantaged (Kurdish) and advantaged (Turkish) group members in a conflict-ridden intergroup context.

\section{Imagined intergroup contact theory}

Recent developments in contact literature have shown that contact strategies may be implemented even in the absence of direct, face-to-face contact between group members and these indirect forms of contact may be equally effective in improving intergroup attitudes and behaviors (Vezzali, Hewstone, Capozza, Giovannini, \& Wölfer, 2014). One of the most practical indirect forms of contact strategies is suggested to be the imagined intergroup contact strategy 
(Turner et al., 2007), which involves the use of a mental simulation of a pleasant intergroup encounter to promote positive attitudes towards outgroups. Since the introduction of the theory, evidence confirming the benefits of imagined intergroup contact for improving intergroup attitudes and behaviors has been compiled (for meta-analysis see Miles \& Crisp, 2014). For example, it has been shown that imagined contact led to more positive explicit and implicit attitudes (Husnu \& Crisp, 2010; Turner \& Crisp, 2010; Vezzali, Capozza, Giovannini, \& Stathi, 2012), physiological responses (West, Turner, \& Levita, 2015), increased contact self-efficacy (Stathi et al., 2011) and positive behavioral intentions (Cameron, Rutland, Turner, HolmanNicolas, \& Powell, 2011; Vezzali, Capozza, Stathi, \& Giovannini, 2012), as well as reduced intergroup threat (Bagci, Piyale, Bircek, \& Ebcim, 2017) and anxiety (e.g., Kuchenbrandt, Eyssel, \& Seidel, 2013; Stathi, Tsantila, \& Crisp, 2012). It has also been found that the effects of imagined contact can generalize to secondary non-related outgroups (Harwood, Paolini, Joyce, Rubin, \& Arroyo, 2011).

Although research has demonstrated the benefits of imagined contact as regards improved intergroup relationships, imagined contact has been rarely applied among minority group members (but see Bagci, Piyale, \& Ebcim, 2018; Bagci, Stathi, \& Piyale, in press; Stathi \& Crisp, 2008) and no research to date has examined specifically whether imagined contact may produce the suggested unintended consequences of direct contact, i.e., reduced motivation to act collectively on behalf of the ingroup (e.g., Dixon et al., 2010). To our knowledge, the only two studies examining the role of imagined contact on variables related to collective action investigated whether imagined contact increased advantaged group members' support for disadvantaged group members' rights (see Bagci et al., 2018; Carvalho-Freitas \& Stathi, 2017). We aim to extend this literature by examining the role of imagined intergroup contact on 
collective action tendencies supporting ingroup rights. Using both advantaged and disadvantaged group members, we also tested whether perceived discrimination, ethnic identification, relative deprivation, and positive outgroup attitudes mediated these effects.

\section{Intergroup contact and collective action}

Although intergroup contact theory has received impressive empirical support (Hodson \& Hewstone, 2013; Pettigrew \& Tropp, 2006), whether contact tackles prejudice and discrimination at the societal level has been questioned since the beginning of the $21^{\text {th }}$ century. Dixon, Durrheim, and Tredoux (2007) highlighted the negative associations between intergroup contact and support for ingroup rights among minority group members. Hence, building positive ties between different groups may change group members' construals about relative group positions, whereby individuals start to believe that groups are more closely related to each other and the social system is fairer (Tropp, Hawi, Van Laar, \& Levin, 2012). These suggestions and relevant empirical findings were explained by Wright and Lubensky (2009), who suggested that intergroup contact and collective action may indeed function via opposing motivations; while successful intergroup contact is likely to decrease ingroup identification, reduce salience of intergroup inequality, provide permeability in group boundaries, and promote positive perceptions of the advantaged group, successful collective action requires individuals to be highly identified with their ingroup, recognize intergroup inequality, consider groups as impermeable, and hold negative perceptions of the advantaged outgroup (see also van Zomeren, Postmes, \& Spears, 2008; van Zomeren, Spears, Fischer, \& Leach, 2004). Further empirical research has confirmed that direct intergroup contact may indeed have a "sedative effect" among disadvantaged group members (Cakal, Hewstone, Schwar, \& Heath, 2011) and create a 
phenomenon that is often referred to as the "irony of harmony" (Saguy, Tausch, Dovidio \& Pratto, 2009; Saguy et al., 2017).

More recent research has suggested possible conditions under which intergroup contact may not have negative outcomes for collective action. For example, Reimer et al. (2017) distinguished the role of positive and negative contact on both minority and majority participants' collective action tendencies. The authors demonstrated that negative contact with heterosexuals (but not positive contact) increased perceived discrimination and ingroup identification, which were in turn associated with increased collective action tendencies among LGBT individuals. Using multilevel analyses at the societal level, Kauff, Green, Schmid, Hewstone, and Christ (2017) found that intergroup contact had a mobilizing effect, instead of a sedative effect, among minority group members in social contexts where majority group members reported positive contact experiences. Becker, Wright, Lubensky, and Zhou (2013) found that when advantaged group members clearly indicated the illegitimacy of the inequality, intergroup contact did not lead to decreased collective action among disadvantaged group members. In a recent review, Pettigrew and Hewstone (2017) indicated that contact may increase collective action tendencies through increased relative deprivation. Therefore, current research highlights that contrary to the premise of 'irony of harmony', under some conditions intergroup contact may be also associated with increased collective action.

\section{Contact and collective action among advantaged group members}

Although collective action tendencies have been mostly studied from the perspective of minority group members, previous research has examined how intergroup contact may influence support for collective action among majority group members too. Yet, the majority of studies explored whether advantaged group members' contact with disadvantaged group members is 
related to collective action on behalf of the disadvantaged group (see Bagci \& Çelebi, 2017; Verkuyten \& Martinovic, 2006). It is possible that during a positive intergroup contact experience, majority group members would feel relatively advantaged, which would in turn promote collective action on behalf of disadvantaged group members (Reimer et al., 2017).

Previous research, however, rarely investigated whether intergroup contact may lead advantaged group members to take collective action on behalf of their own ingroup, probably because advantaged groups may already exert control through their powerful position and consequently may not need to act collectively to secure their ingroup's rights (Saab, Harb, \& Moughalian, 2017). Nevertheless, evidence suggests that advantaged group members in conflict settings may also display motivation to maintain their ingroup's rights through collective action. For example, with recent changes in anti-immigration and asylum seeking policies, Europeans, as the advantaged group, have also started to engage in collective action in order to preserve their ingroup's interests (e.g., Delcker, 2015; Saab et al., 2017). Therefore, in societies where perceived conflict and competition is high and status differences are impermeable, advantaged group members may display the tendency to engage in collective action on behalf of their ingroup with a strong desire to maintain and strengthen their powerful position in the society (e.g., van Zomeren \& Iyer, 2009).

Nevertheless, the association between direct contact and collective action tendencies among advantaged group members is far from being fully explored. Çakal, Hewstone, Güler, and Heath (2016) examined the associations between direct intergroup contact and collective action tendencies among the advantaged Turks in Turkey and found that contact was not directly related to collective action tendencies, but there was an indirect negative association through decreased levels of perceived threat. Saab et al. (2017) found that contact was related to lower levels of 
violent collective action tendencies among Lebanese nationals (advantaged), but no significant associations were found regarding non-violent collective action tendencies. These findings offer preliminary evidence for the possible associations between direct contact and collective action among advantaged group members and highlight the need for further studies to investigate possible effects of imagined contact on advantaged group members' collective action tendencies.

\section{Mediators of the contact - collective action path}

Previous research has identified a number of mediators of the association between contact and collective action. Studies have shown that intergroup contact is related to reduced levels of perceived discrimination (Dixon et al., 2010; Ellison \& Powers, 1994). For example, Saguy and Chernyak-Hai (2012) found that commonality-focused interaction with outgroup members led minority group members to perceive lower status hierarchy and to be less likely to attribute negative treatment to discrimination. Perceived discrimination, in turn, is a major precursor of collective action (Wright \& Tropp, 2002). Motivation for collective action is often sustained by greater levels of injustice and inequality towards the ingroup (e.g., SIMCA, Social Identity Model of Collective Action, van Zomeren et al., 2008). In line with this, Tropp et al. (2012) demonstrated that cross-group friendships with majority group members predicted lower levels of ethnic activism over time via decreased perceived discrimination.

Other studies have suggested that intergroup contact may reduce collective action tendencies by decreasing ingroup identification. Pettigrew (2009) suggested that intergroup contact is likely to lead to the reappraisal of ingroup membership and distance individuals from their own ingroup, a process known as "deprovincialization". In line with this assumption, direct intergroup contact has been suggested to reduce ingroup identification and to be related to higher levels of social distancing from the ingroup (Verkuyten, Thijs, \& Bekhuis, 2010). On the other 
hand, ingroup identification is at the core of collective action and motivates group members to fight for ingroup rights (van Zomeren et al., 2008). Previous research has demonstrated that cross-group friendships with Whites were related to lower interest in collective action through decreased levels of ingroup identification (Tausch, Saguy, \& Bryson, 2015).

We suggest that relative deprivation may also play a critical role on the effects of imagined contact on collective action tendencies. Previous research has indicated intergroup contact to be related to reduced relative deprivation among both disadvantaged and advantaged group members (e.g., Ellison \& Powers, 1994). In turn, relative deprivation is a key process in SIMCA (van Zomeren et al., 2008). Accordingly, as a result of social comparison with advantaged group members, disadvantaged group members often perceive stronger injustice affecting the ingroup and experience emotional arousal such as anger and resentment towards the outgroup, overall leading them to become more engaged in collective action (e.g., Dixon et al., 2010; Van Zomeren \& Iyer, 2009). Confirming this suggestion, Cakal et al. (2011) found that direct contact led to reduced relative deprivation and thereby related to higher levels of collective action and support for policies favoring the disadvantaged Blacks in South Africa.

Finally, a fourth process that may mediate the association between intergroup contact and collective action tendencies is positive outgroup attitudes. The positive role of intergroup contact on intergroup attitudes has been shown in ample research (e.g., Pettigrew \& Tropp, 2006). On the other hand, collective action is fueled by negative emotions and anger towards the outgroup and dislike is usually a prerequisite for the formation of these negative emotions (Wright \& Lubensky, 2009; van Zomeren et al., 2008). Therefore, one way intergroup contact may create a sedative effect among group members and deter individuals from collective action is by bringing group members together and building close intergroup relationships characterized by positive 
intergroup attitudes and behaviors. Confirming this, Tausch et al. (2015) demonstrated that contact was related to reduced collective action intention through creating more positive outgroup attitudes.

\section{The current research}

We conducted two simultaneous studies in Turkey within the intractable Turkish-Kurdish conflict setting, where Kurdish people constitute a disadvantaged group, as they have been a historically oppressed sub-culture in Turkey s (e.g., Mutlu, 1996). The Kurdish issue in Turkey has been debated since the 1990's when violence between separatist groups and the State gave rise to violent and armed encounters in the Southeast parts of Turkey, where Kurdish people are the numerical majority (approximately $18 \%$ of the total population in Turkey, Konda, 2011). As a result of military attacks, thousands of people from both sides have died (Gocek, 2011), with many others forced to migrate to other parts of the country. Previous research also showed that both groups are likely to blame each other for the conflict and display negative intergroup stereotypes and attitudes (e.g., Bilali, Çelik, \& Ok, 2014), and that direct intergroup contact is likely to promote positive intergroup attitudes and support for multiculturalism (Bagci \& Celebi, 2017). Moreover, intergroup contact was found to be related to lower collective action tendencies through decreased levels of perceived threat among both groups (Çakal et al., 2016), and to lead Kurds to endorse pro-Kurdish conflict narratives to a lesser extent (Ulug \& Cohrs, 2017). A further correlational study among both groups indicated that positive contact, but not negative contact, was indirectly related to lower collective action tendencies through lower ingroup identification (Bagci \& Turnuklu, in press). Nevertheless, imagined contact research among Kurds revealed mixed findings; an imagined contact study among the Kurds (Bagci et al., 2018, Study 3) showed that imagined contact led to decreases in intergroup anxiety and increases 
in perceived majority group's attitudes towards the minority group, while two other studies conducted in a more tense and conflictual area in Turkey demonstrated imagined contact to increase perceived discrimination (Bagci et al., in press, Study 2 and 3).

The current study extends previous research on intergroup relations in several ways. First, although cross-sectional and longitudinal research has provided evidence for the associations between direct contact and collective action tendencies, no research to date has examined the effect of imagined contact on these variables. Imagined experiences are known to result in similar responses to actual contact (e.g., Giacobbe, Stukas, \& Farhall, 2013) and imagined contact has been proven to provide many of the previously distinguished direct contact effects (Miles \& Crisp, 2014). Second, previous research explored historically disadvantaged group members recruited from intergroup settings where intergroup conflict may not be a salient aspect of current intergroup relations (e.g., Tausch et al., 2015). Relevant studies have shown that the link between contact and collective action may depend on macro-level societal factors, such as the extent to which majority group members have positive intergroup experiences in a specific social environment (Kauff et al., 2017). Third, previous research primarily relied on the perspective of minority group members without addressing whether contact may be related to collective action tendencies on behalf of the ingroup among advantaged group members (but see Bagci \& Turnuklu, in press; Çakal et al., 2016; Saab et al., 2017). Finally, by incorporating simultaneously key, theory-driven mediators of the contact and collective action path, the current research aims to provide a clear understanding of the potential effects of imagined contact.

\section{Study 1}

Study 1 tested imagined contact effects on collective action tendencies among the disadvantaged Kurds. Based on previous findings in the literature showing the sedative effects of 
direct intergroup contact among minority group members, we hypothesized that imagining a positive and pleasant intergroup encounter with an unknown Turk would decrease collective action tendencies among Kurds. We further expected these effects to be mediated by decreased perceived discrimination, relative deprivation, and ethnic identification, as well as increased positive outgroup attitudes.

\section{Method}

\section{Participants and Procedure}

We recruited a total of 82 Kurdish participants from Cizre, Şırnak, located in the Southeast part of Turkey, where the majority of residents are from Kurdish ethnic background. Two participants were excluded from the study as they were outliers on multiple measures and the final sample was constituted of $80^{1}$ participants (59 Males and 21 Females, $M_{\text {age }}=33.95, S D$ = 6.76). Participants rated their subjective socio-economic status ("How would you rate your socio-economic status?", based on a response scale from $1=$ very low to $4=$ very high) as middle social class with a mean of $2.44(S D=.99)$. The location has experienced frequent violent conflict between separatist groups and Turkish military over the last decade, and data collection occurred in September-October 2017, in the aftermath of various armed encounters during 2016. Participants were recruited through the social network and with the help of a research assistant, and online questionnaires were filled in public places. At the end of data collection, all participants were debriefed and received a small monetary payment for their participation.

\footnotetext{
${ }^{1} \mathrm{~A}$ post-hoc $\mathrm{G}^{*}$ Power analysis showed that with an alpha level of $.05(N=80)$, two groups, five dependent variables, and an effect size of $f=.35$, achieved power was .99 .
} 
We randomly allocated participants to one of two conditions $\left(N_{\text {control }}=43, N_{\text {contact }}=37\right)$. In the imagined contact condition, participants were given a standard imagined contact scenario (Bagci et al., 2017; Stathi \& Crisp, 2008):

"Please think about a random midday, you are sitting alone at a familiar cafe. Imagine that an unknown Turkish person approaches you and asks your permission to sit on your table. You start to talk with this person for 20-30 minutes. After the person leaves, you think about how pleasant and interesting your conversation was. Now, please think what you could have talked about with this person and describe the encounter in five-six sentences."

In line with previous research, in the control condition participants were given a noncontact relevant scene to imagine:

"Please imagine that you are in a trekking trip for two minutes. Describe the details of the scene (what you see, who is with you,...) and write down your experience in five-six sentences."

\section{Measures}

Unless otherwise stated, all items ranged from 1 (strongly disagree) to 7 (strongly agree), with higher scores indicating higher levels on the relevant construct. Perceived discrimination was measured by two items (Tropp et al., 2012) and assessed the extent to which participants thought they were personally discriminated because of their ethnic background and the extent at which they thought members of their ethnic group were discriminated because of their ethnic background $(r=.91, p<.001)$. The response scale ranged from 1 (not at all) to 7 (all the time). Ingroup identification was measured by three items assessing the level of connectedness and belongingness to the ethnic ingroup (Verkuyten \& Yildiz, 2006, e.g., "I identify with the Kurdish ethnic group" and "I feel connected to Kurds"). The internal reliability of the scale was excellent 
(Cronbach's Alpha $=.95)$. Relative deprivation was measured by two items assessing relative deprivation in terms of economic and social rights (Cakal et al., 2011; Leach, Iyer, \& Pedersen, 2007, "Kurds are economically disadvantaged compared to Turks" and "Kurds are socially disadvantaged compared to Turks", $r=.58, p<.05)$. Outgroup attitudes were measured by the feeling thermometer (e.g., Esses, Haddock, \& Zanna, 1993) that asked participants to rate how favorably they felt towards Turks on a range between 0 degree (extremely unfavorable) to 100 degrees (extremely favorable). Collective action tendencies were measured by a three-item scale (Çakal et al., 2016) that assessed how much participants would be willing to engage in collective action in support of their ingroup's rights (e.g., "I would be willing to sign a petition to improve the current situation of my ethnic group in Turkey" and "I would be willing to sign up for a neighbourhood project to improve the conditions for my ethnic group in my neighbourhood"). The scale had excellent reliability (Cronbach's Alpha $=.95)$.

\section{Results}

Variables controlling for alternative explanations. To ensure that differences among conditions were not attributed to the valence or difficulty of the task, after the manipulation, participants were asked to rate to what extent they found the imaginary task interesting, difficult, and positive (see Harwood et al., 2011; West \& Bruckmüller, 2013; Yetkili, Abrams, Travaglino, \& Giner-Sorolla, 2018). Independent samples t-tests showed that were no differences regarding perceived difficulty of the task, $t(77.15)=1.10, p=.27$, and positivity of the task, $t(54.45)=$ $1.56, p=.13$. There was, however, a significant difference between the two conditions in terms of interest, $t(55.60)=3.03, p=.004$; the control condition $(M=6.56, S D=.98)$ was found to be more interesting compared to the imagined contact condition $(M=5.60, S D=1.71)$. To allow a stringent test of the effects of the condition, these were added as covariates in the main analyses. 
Group differences. A MANCOVA analysis was conducted to investigate the effects of condition on perceived discrimination, ethnic identification, relative deprivation, outgroup attitudes, and collective action tendencies, after controlling for interest, difficulty, and positivity of the task. The final model demonstrated multivariate effects of interest, $F(5,71)=3.37, p=.01$, $\eta_{p}^{2}=.19$, positivity, $F(5,71)=3.74, p=.01, \eta^{2}{ }_{p}=.21$, and difficulty of the task, $F(5,71)=2.24, p$ $=.06, \eta_{p}^{2}=.14$. Furthermore, results revealed a significant multivariate main effect of condition, $F(5,71)=7.59$, Wilks' Lambda $=.65, p<.001, \eta^{2}=.35$. A further examination of univariate effects demonstrated that condition had a significant main effect on perceived discrimination, $F(1,75)=31.35, p<.001, \eta^{2}{ }_{p}=.30$; ethnic identification, $F(1,75)=9.61, p=.003, \eta^{2}{ }_{p}=.11$; and collective action tendencies, $F(1,75)=11.90, p=.001, \eta^{2}{ }_{p}=.14$. Accordingly, compared to the control condition, participants in the imagined contact condition reported higher levels of perceived discrimination $\left(M_{\text {contact }}=6.01, S D=1.25, M_{\text {control }}=3.79, S D=1.87\right)$, ingroup identification $\left(M_{\text {contact }}=6.28, S D=.98, M_{\text {control }}=5.64, S D=1.14\right)$, and collective action tendencies $\left(M_{\text {contact }}=5.98, S D=1.21, M_{\text {control }}=5.20, S D=1.13\right)$. The effect of condition on outgroup attitudes $\left(F(1,75)=.06, p=.81, \eta^{2}{ }_{p}=.001\right)$ and relative deprivation, $(F(1,75)=1.56, p$ $\left.=.22, \eta_{p}^{2}=.02\right)$ was not significant (see Table 1$)$.

Indirect effects. We used PROCESS Macros (Model 4, Hayes, 2013) to test whether the effect of condition on collective action tendencies was significantly mediated by perceived discrimination and ingroup identification after controlling for interest, difficulty, and positivity of the task. The bootstrapping procedure (5000 samples) with $95 \%$ confidence intervals was performed to test for indirect effects. Condition was a significant predictor of perceived discrimination $(b=2.18, p<.001)$ and ethnic identification $(b=.80, p=.003)$. Among the covariates, interest $(b=.31, p=.01)$ and positivity $(b=-.37, p=.01)$ significantly predicted 
collective action tendencies. Moreover, perceived discrimination $(b=.33, p<.001)$ and ethnic identification $(b=.40, p<.001)$ were significant predictors of collective action tendencies. Further bootstrapping analysis indicated that both perceived discrimination $(b=.71, S E=.19$, $95 \% \mathrm{CI}[.18, .42])$ and ethnic identification $(b=.32, S E=.15,95 \%$ CI $[.08, .72]$ significantly mediated these effects. ${ }^{2}$

\section{Free-response data analysis}

As the results of the study showed imagined contact to increase perceived discrimination and ingroup identification, and thereby collective action tendencies, we further investigated participants' free-response contact descriptions during the imagined contact task. Although participants' own ratings of task positivity were not different between the control and experimental conditions, and the task instructed participants to imagine a 'positive and interesting' contact scenario, we believed further analysis of the content of the imagined contact conversations may shed light into our quantitative findings. Six main themes emerged as being frequently observed in participants' descriptions: avoidance or expectation of prejudice, salience of group membership, positivity of contact experiences, perceived group differences, perceived group similarities, and contact conditions. Each participant's descriptions were coded and then included under one or more themes. The coding procedure was completed by two researchers independently (percent agreement ranged from $81.1 \%$ to $91.1 \%$ ), and then each description was coded into one or more categories upon researchers' agreement. Confirming participants' own

\footnotetext{
${ }^{2}$ Additional analyses were conducted to analyze whether imagined contact effects on the mediators and dependent variable were different across participants who perceived the task as more positive or negative. Two significant interactions emerged; imagined contact increased ingroup identification among participants who perceived imagined contact to be negative $(b=1.90, p<.001)$, but not among those who perceived it as positive $(b$ $=.12, p=.71)$. Imagined contact also increased relative deprivation only among participants who perceived imagined contact to be negative $(b=1.23, p=.001)$, but not among those who perceived it as positive $(b=-.21, p=$ .54). The main effects of condition were intact with the addition of these interactions. Moderated mediations were only significant as regards relative deprivation $(b=-.21, S E=.14)$, showing relative deprivation as a significant mediator only among participants who reported lower levels of positivity $(b=.42,95 \% \mathrm{Cl}[.02,1.83])$.
} 
ratings, we found a number of positive elements in participants' descriptions (namely tolerance, empathy, enjoyment, desire for future contact, pleasantness, reciprocal respect). More specifically, $71.05 \%$ of participants indicated a positive aspect of the interaction (e.g., "Our interaction would involve tolerance and reciprocal empathy and I would like to see this person again", "Our conversation would be pleasant and sincere, like a friendship"). Nevertheless, such positivity was often accompanied by other themes. For example, some participants $(26.32 \%)$ talked about the expectation of prejudice or hope that the interaction would not involve any prejudicial attitudes (e.g., "I would try not to seem prejudiced and hope that it would be an enjoyable conversation", and "It would be a warm interaction around the issues between Turks and Kurds, and I would tell him/her that I hope that the prejudice will end"). Some participants' descriptions also included elements about group differences (21.05\%) (e.g., "We would have good time. We would enjoy our conversation without touching into group differences", and "I would try to make the interaction pleasant, but I wouldn't keep it long because we would have different opinions"), as well as similarities (7.89\%) (e.g., "We talked about unemployment, they also have the same problem and we complained about the same problem"). Nevertheless, approximately for one third of the participants (28.95\%), the imagined contact scenario seemed to make group memberships salient (e.g., "I would keep good conversation since he/she came to my table. But after a while, there would certainly be a problem since we belong to different ethnic groups", "I have seen that he/she is not discriminatory towards me, he/she defends brotherhood between societies and he/she thinks Kurds exist as a society"). Other participants indicated that the conversation would be positive under certain conditions (15.79\%) (e.g., "Our conversation would be nice if the other person is tolerant; we would have a friendly interaction", "I would show hospitality if he/she came to my table, and try to keep it pleasant without getting 
into politics"). Overall, these findings suggest that imagined contact in such a conflictual context may have rendered group memberships and group related concerns more salient, and thereby fostered collective action tendencies.

\section{Discussion}

Study 1 showed that imagined contact increased collective action tendencies among the disadvantaged Kurds and these effects occurred through increased perceived discrimination and ethnic identification. The reasons underlying why imagining a positive encounter increased collective action tendencies among Kurds may be explained by a few mechanisms. One reason may be the nature of the conflict-ridden context which provides a unique setting where interethnic relationships between the two groups have deteriorated over time, with Kurds becoming an oppressed minority group (Bagci \& Çelebi, 2017). It is possible that in specific intergroup contexts characterized by extreme conflict, imagined contact may not produce the expected equality illusion that is granted by positive contact, but instead fuel collective action by increasing the perception of discrimination and ingroup identification. Confirming this finding, few empirical research studies have shown intergroup contact to increase perceived discrimination among minority group members (Poore, Gagne, Barlow, Lydon, Taylor, \& Wright, 2002).

An alternative explanation is the salience of ingroup identities during the imagined intergroup contact scenario. Previous research suggested that in particular commonality-focused positive contact is likely to reduce collective action tendencies (e.g., Saguy et al., 2009) and direct forms of intergroup contact may be related to increased motivation for social change when group membership and distinction is especially pronounced. In a study of the associations between direct and extended contact and motivation for social change, Vezzali, Saguy, 
Andrighetto, Giovannini, and Capozza (2016) found that extended contact was directly associated with increased social change motivation, since extended contact involves membership salience to a greater extent, compared to direct contact. Therefore, in the context of imagined contact, one can assume that group membership would be more salient compared to direct contact and that ingroup identities and inequality would become even more critical than before, resulting in increased collective action tendencies. Our free-response data analysis also indicated that although the majority of imagined contact descriptions was described as positive, participants' imagined experiences also involved group membership salience, differences and similarities between Turks and Kurds, as well as prerequisite conditions under which imagined contact would be positive. Hence, for the Kurds who live in an area of conflict, imagined contact seemed to make ethnic group differences even more salient thereby producing a mobilizing effect.

Our findings are in some ways inconsistent with recent studies showing contact to have sedative effects within the Turkish-Kurdish setting (Çakal et al., 2016; Uluğ \& Cohrs, 2017). One reason for this may be because, unlike these other studies, we focused on Kurdish participants from a small town in Southeastern Turkey, where participants are likely to have directly experienced armed and violent conflict. This area is also numerically dominated by Kurds, which suggests that an imagined contact scenario may be an even more salient form of contact for this group who generally have lower opportunities to form direct contact.

Furthermore, unlike other studies, our data were collected after the government's reconciliation efforts, which aimed to grant the Kurdish group some minority rights, ceased in 2015 and the cycle of conflict reescalated. This may have led imagined contact to fuel conflict-related perceptions rather than exerting a demobilizing sedative effect. Accordingly, an imagined 
contact study conducted in the same area with the aim of exploring imagined contact effects on acculturation outcomes, demonstrated imagined contact to increase perceived discrimination and culture maintenance and to reduce contact participation via decreased levels of perceived social acceptance (Bagci et al., in press).

\section{Study 2}

Study 1 provided evidence for the effects of imagined contact on mobilizing disadvantaged group members; imagining a positive and pleasant intergroup encounter with an unknown Turk did not undermine Kurds' motivation for collective action, but instead led them to display significantly higher levels of collective action tendencies through increased perceived discrimination and ingroup identification, which is in line with some of the previous studies in direct contact literature showing contact not to have a sedative effect under some circumstances (e.g., Kauff et al., 2017; Reimer et al., 2017). In Study 2, we concentrated on the majority group; previous research has shown that majority group members may also engage in collective action on behalf of their own ingroup, especially in conflict settings and direct contact may have sedative effects among the advantaged too (Çakal et al., 2016; Saab et al., 2017). Nevertheless, whether indirect contact strategies, such as imagined contact, may alter collective action tendencies is unknown.

We argued that two scenarios would be equally likely to occur among the advantaged Turks. Based on the literature which has shown direct contact to be related to decreased collective action tendencies among the majority group (Bagci \& Turnuklu, in press; Çakal et al., 2016; Saab et al., 2017), we could expect imagined contact to produce a similar effect and decrease collective action tendencies through improving outgroup attitudes and decreasing perceived discrimination, ingroup identification, and relative deprivation. Hence, although Study 
1 demonstrated that imagined contact increased collective action among the disadvantaged Kurds, it is also known that various group processes such as intergroup anxiety, intergroup contact, and collective action may operate differentially among the majority and minority group members (e.g., Tropp \& Pettigrew, 2005; Tropp, Wright, \& Mazziotta, 2017; Wright \& Lubensky, 2009).

On the other hand, one could argue that advantaged and disadvantaged group members may display similar group-based perceptions, such as perceived intergroup threat and social change motivation, especially in conflict settings (Çakal et al., 2016). That is, in conflict settings the advantaged group may still perceive elements of disadvantage and feel that the ingroup rights are being challenged or threatened. Therefore, it could be expected that imagined contact would also mobilize Turks who are recruited from a conflictual intergroup setting.

\section{Method}

\section{Participants and Procedure}

A total of 145 student participants were initially recruited for the study, but we excluded 14 participants who self-identified with an ethnic background other than Turkish and four participants who were outliers on multiple measures. This resulted in the inclusion of $127^{3}$ participants in the final sample (53 Males and 74 Females, $M_{a g e}=22.43, S D=5.03$ ). The mean subjective socio-economic status of participants (ranging from $l=v e r y$ low to $4=v e r y$ high) was $2.54(S D=.63)$. Participants were recruited from a private university in Istanbul and online forms were completed in psychology labs with the help of research assistants. All participants

\footnotetext{
${ }^{3}$ A post-hoc $G^{*}$ Power analysis showed that with an alpha level of $.05(N=127)$, two groups, five dependent variables and an effect size of $f=.12$, achived power was .85 .
} 
were debriefed and offered a small monetary payment for their participation at the end of data collection.

The experimental procedure was exactly the same as in Study 1, except that participants in the contact condition were asked to think about meeting an unknown Kurdish person in a familiar cafe $\left(N_{\text {control }}=68\right.$ and $\left.N_{\text {contact }}=59\right)$. Similar to Study 1, participants were instructed to imagine the contact as pleasant and interesting. In the control condition, participants were asked to imagine details of a trekking trip (see Study 1).

\section{Measures}

Unless otherwise stated, all response scales ranged from 1 (strongly disagree) to 7 (strongly agree). Perceived discrimination was measured by one item adapted from Tropp et al. (2012), assessing how much participants perceived discrimination at the personal level (see Study 1). Ingroup identification was assessed by Verkuyten and Yildiz's (2006) ethnic identification scale (three items, see Study 1, Cronbach's Alpha =.86). Similar to Study 1, relative deprivation was originally measured by a two-item scale (Cakal et al., 2011), but due to the low internal consistency across the two items, a single item which measured relative deprivation in terms of social rights was used (see Study $1, r=.10, p=.27$ ). Outgroup attitudes were assessed by a single-item feeling thermometer (Esses et al., 1993, see Study 1). Collective action tendencies was measured by a three-item scale (Çakal et al., 2016, see Study 1, Cronbach's Alpha $=.89$ ) and assessed how much participants were likely to engage in collective action favoring their ingroup rights.

\section{Results}

Variables controlling for alternative explanations. Results of independent samples t-tests demonstrated that condition had a significant effect on the interest, $t(125)=4.09, p<.001$, and 
positivity of the task, $t(125)=3.66, p<.001$. Accordingly, the control condition $(M=5.72, S D=$ 1.17) was perceived to be more interesting compared to the imagined contact condition $(M=$ $4.75, S D=1.52)$. Similarly, participants perceived the control condition $(M=6.22, S D=1.03)$ to be more positive than the imagined contact condition $(M=5.49, S D=1.21)$. Perceived difficulty of the task did not differ significantly between the two conditions. As in Study 1, these items were treated as covariates in further analyses.

Group differences. A MANCOVA analysis was performed to test the effect of condition on perceived discrimination, ingroup identification, relative deprivation, outgroup attitudes, and collective action tendencies. Results showed no significant multivariate effect of interest of the task, $F(5,118)=.90, p=.49, \eta^{2}{ }_{p}=.04$ and difficulty of the task, $F(5,118)=1.34, p=.25, \eta^{2}{ }_{p}=$ .05 , whereas perceived positivity had a significant effect on the model, $F(5,118)=2.82, p=.02$, $\eta^{2}=.11$. Moreover, a significant multivariate effect of condition was observed, $F(5,118)=3.14$, Wilks' Lambda $=.88, p=.01, \eta_{p}^{2}=.12$. Univariate effects revealed that condition had no significant effect on ingroup identification, $F(1,122)=3.67, p=.67, \eta_{p}^{2}=.001$. However, we observed a significant effect of condition on outgroup attitudes, $F(1,122)=5.94, p=.02, \eta^{2} p=.05$ and perceived discrimination, $F(1,122)=5.10, p=.03, \eta^{2}{ }_{p}=.04$, and a marginally significant effect on relative deprivation, $F(1,122)=2.99, p=.086, \eta^{2}{ }_{p}=.02$, and collective action tendencies, $F(1,122)=3.67, p=.058, \eta^{2}=.03$. Findings indicated that, compared to participants in the control condition, participants in the imagined contact condition perceived discrimination $\left(M_{\text {contact }}=2.20, S D=1.58, M_{\text {control }}=1.63, S D=1.15\right)$ and relative deprivation $\left(M_{\text {contact }}=2.98, S D\right.$ $\left.=2.03, M_{\text {control }}=2.34, S D=1.50\right)$ to a greater extent, displayed more positive outgroup attitudes $\left(M_{\text {contact }}=66.75, S D=22.94, M_{\text {control }}=62.68, S D=22.35\right)$, and reported higher levels of collective action tendencies $\left(M_{\text {contact }}=5.01, S D=1.64, M_{\text {control }}=4.58, S D=1.92\right)($ see Table 2$)$. 
Indirect effects. We used PROCESS Macros (Model 4, Hayes, 2013) to examine whether perceived discrimination, relative deprivation, and positive outgroup attitudes significantly mediated the effect of condition. Interest, difficulty, and positivity of the task were controlled in the model as covariates. Findings showed that none of the covariates had significant associations with collective action tendencies. Condition had a significant effect on perceived discrimination $(b=.60, p=.03)$ and positive outgroup attitudes $(b=9.99, p=.02)$, and a marginally significant effect on relative deprivation $(b=.59, p=.089)$. In turn, none of the mediators significantly predicted collective action tendencies $(b=.15, p=.21$ for perceived discrimination, $b=.02, p=$ .87 for relative deprivation, $b=.01, p=.32$ for outgroup attitudes). Bootstrapping analysis showed that none of the mediators significantly mediated the relationship between condition and collective action $(b=.09, S E=.09,95 \% \mathrm{CI}[-.02, .35]$ for perceived discrimination; $b=.01, S E$ $=.07,95 \%$ CI $[-.11, .19]$ for relative deprivation; and $b=.08, S E=.09,95 \%$ CI $[-.05, .35]$ for outgroup attitudes $)^{4}$

\section{Analyses of free-response data}

Similar to Study 1, we further explored participants' descriptions of the imagined contact scenario by using the same six themes that have been frequently mentioned in participants' responses (percent agreement between two independent researchers ranged between $71.9 \%$ and 93\%). Similar to Study 1, the majority of participants included positive elements in their descriptions such as tolerance, empathy, perspective-taking, pleasantness and fun, as well as friendliness (56.90\%). For example, some participants stated: "I can understand from his/her talk

\footnotetext{
${ }^{4}$ Additional analyses showed that there was a significant interaction between condition and perceived positivity on outgroup attitudes ( $b=9.69, p=.02)$, such that imagined contact increased positive outgroup attitudes only among participants who perceived imagined contact as a positive experience $(b=17.57, p=.008)$, but not among those who perceived it as negative $(b=-1.80, p=.78)$. The main effect of condition was still intact after the addition of the interaction.
} 
that he/she enjoys life, he/she likes to help, is respectful, and he/she is not arrogant" and "He/she is a very friendly person, we talked about football. He/she invited me to a place for the weekend. I think she/he is a nice person and believe we can be friends for a long time". Nevertheless, only few participants described their interaction with solely such positive terms; $29.31 \%$ of the sample mentioned discrimination or prejudice (e.g., "First, we talked about our shared activities. Then, he/she talked about the discrimination perceived by his people and I would like to hear about that in person"). Moreover, for many participants, group memberships were salient (34.48\%) (e.g., "I would make an effort not to think about his/her group membership. Everyone knows that such a conversation would not end up well..." and "...he/she should not say that he/she is Kurdish, because I would not tell him/her that I am a Turk...”). Others also indicated similarities and shared activities $(29.31 \%)$ (e.g., We first talked about why he/she wanted to talk to me. Then it came to political ideas and I realized how similar our opinions were"), whereas some participants mentioned perceived differences $(8.62 \%)$ (e.g., "This would be a controversial conversation around different opinions. I would doubt that I would see him/her again”). Finally, a number of people also described their contact experience to be positive if some conditions were satisfied (22.41\%) (e.g., "We could have talked about art, music and history and our common interests. If it goes around education and science, it could have gone better. I wouldn't like him/her to get into political issues. If he/she talks reasonably like an ordinary citizen, it would go well. The first impression I would get should be based on trust and not make me uncomfortable" and "We could have talked about philosophy, history, and science. These may include common interests and hobbies. However, I think we wouldn't be exchanging ideas about political issues"). Overall, as in Study 1, these contents indicate that although contact descriptions included positive elements such as common interests and a pleasant interaction, for many participants it included additional 
comments where they evaluated the interaction based on group memberships and prejudicerelated concerns.

\section{General Discussion}

Recent research has shown that, although intergroup contact leads to improved intergroup relationships, it may also create an illusional sense of intergroup equality and thereby hinder interest and motivation to engage in collective action that is sometimes an indispensable milestone towards social change (e.g., Saguy et al., 2017). While the sedative effects of contact have been confirmed in many studies, recent research has highlighted that contact may not be unconditionally related to reduced collective action tendencies, and may in fact increase it under some circumstances (e.g., Kauff et al, 2017; Pettigrew \& Hewstone, 2017; Vezzali et al., 2016). Motivated by this critical debate, we investigated whether imagining a positive interaction with a Turk (Kurd) would change collective action tendencies through decreased perceived discrimination, ingroup identification, and relative deprivation, as well as increased positive attitudes among both advantaged and disadvantaged group members.

Study 1 showed that imagined contact increased collective action tendencies through increased perceived discrimination and ingroup identification among the Kurds. The mobilizing effect of imagined contact among a minority status group is a critical finding, given that only few studies have demonstrated direct contact to have such effects (e.g., Becker et al., 2013; Kauff et al., 2017). Our findings imply that in a particularly conflictual intergroup setting, imagined contact may increase collective action tendencies among a minority group by increasing ingroup identification and perceived discrimination. Study 2 also showed that imagined contact increased collective action tendencies among the advantaged Turks. Moreover, imagined contact increased perceived discrimination and relative deprivation (marginally). This finding is in line with the 
assertion by Pettigrew and Hewstone (2017) that contact may not eventually lead to decreased collective action tendencies, but in fact create relative deprivation and thereby support collective action tendencies. Although, we did not uncover effective explanatory mechanisms among the advantaged group, these results are partly consistent with Çakal et al.'s (2016) study, suggesting that advantageous and disadvantageous group members in conflict settings may not necessarily display divergent psychologies in terms of collective action.

Our free-response data analysis in both studies indicated that simply imagining a positive encounter may not solely involve positive interactional conditions, but at the same time trigger various complex processes such as heightened group membership salience and expectation of prejudice. In both studies, the imagined contact task was found to be relatively positive (although in Study 2, the control condition was significantly more positive), suggesting that the mobilizing effect may not be simply due to the valence of contact (contact being perceived as negative). For example, specific emotions felt towards the imagined contact partner may be assessed in future research, as SIMCA suggests that collective action usually requires individuals to feel resentment or anger towards the outgroup, which then motivates them to act in support of their rights (e.g., van Zomeren et al. 2008). Further research may investigate the characteristics of the imagined contact partner including how the participants felt towards this specific partner, and whether they considered this person to be a typical or normative outgroup member (e.g., Stathi, Crisp, \& Hogg, 2011; Yetkili et al., 2018).

Our findings also showed that although imagined contact had similar effects among both advantaged and disadvantaged group members in terms of collective action tendencies, the strategy had different effects on outgroup attitudes among the two groups. Specifically, Study 1 showed that imagined contact did not have a direct effect on outgroup attitudes among the 
disadvantaged group, whereas Study 2 indicated improved outgroup attitudes as a result of imagined contact. These findings are indeed in line with previous research in direct contact literature demonstrating contact to be less effective among minority group members compared to majority group members (Tropp \& Pettigrew, 2005). Other imagined contact research has also shown that imagined contact may not readily improve outgroup attitudes among the minority group (Bagci et al., 2018; Stathi \& Crisp, 2008). Such findings also suggest that even though outgroup attitudes are often suggested as a process that enhances the sedative effect of contact (e.g., Tausch et al., 2015; Wright \& Lubensky, 2009), these constructs may not be necessarily related, and improved outgroup attitudes may not unconditionally lead to reduced collective action tendencies (e.g., Bagci \& Turnuklu, in press).

Findings also imply the need to improve further the effectiveness of indirect contact strategies in creating more positive intergroup relations. Imagined contact has sometimes yielded unexpected results compared to direct contact and has been shown to backfire under various conditions (e.g., Asbrock, Guttenbrunner, \& Wagner, 2013; Bagci, Stathi, \& Piyale, in press; West \& Bruckmüller, 2013; West \& Greenland, 2016). Other research has also demonstrated indirect contact strategies, such as extended or vicarious contact, to produce unexpected effects such as increased social change motivation and increased intergroup anxiety (Liebkind, Mahönen, Solares, Solheim, \& Jasinskaja-Lahti, 2014; Vezzali et al., 2016). This calls for future research that would reveal under which conditions indirect contact strategies provide the most beneficial outcomes for group members.

The limitations of the current research should be acknowledged. First, the study involved a unique context which provides an excellent milieu for the study of the potential effects of imagined intergroup contact among both disadvantaged and advantaged group members. 
However, our findings may not be comparable to intergroup contexts that are not characterized by intergroup conflict, which suggests that further investigation is necessary. Second, although we included a number of potential mechanisms explaining the effects of imagined contact, further research is needed to examine the mediating roles of other variables such as perceived threat and intergroup anxiety, which potentially decrease after imagined contact (e.g., Bagci et al., 2017; Çakal et al., 2016; Stathi et al., 2012). Especially among the advantaged group members, the proposed mediating processes could not explain how imagined contact increased collective action tendencies. One of the reasons for this may be the relatively lower levels of variance in perceived discrimination and relative deprivation among this group compared to the disadvantaged group. Although previous research has suggested that majority group members may also perceive discrimination and deprivation when their status quo is threatened (e.g., Norton \& Sommers, 2011; Schmitt \& Branscombe, 2002), other potential mediators that have been identified as important mechanisms on the relationship between intergroup contact and outgroup attitudes can be tested within the collective action framework. For example, perspective-taking may play a role on the relationship between imagined contact and collective action tendencies. Moreover, other mediating mechanisms in line with SIMCA such as anger and group efficacy may be investigated to fully explain how imagined contact influences collective action (van Zomeren et al., 2008).

In summary, the current studies investigated for the first time the role of imagined contact on collective action tendencies among disadvantaged and advantaged group members in a conflict-ridden context. Findings demonstrated that imagined contact led to increased collective action tendencies through increased perceived discrimination and ingroup identification among the disadvantaged Kurds. Moreover, among the advantaged Turks, imagined contact also 
enhanced collective action tendencies and increased perceived discrimination and, marginally, relative deprivation. Findings highlight the importance of the socio-cultural context where contact occurs, as well as the type of intergroup contact strategy, in investigating the potential sedative or mobilizing effects of indirect contact strategies. Specifically, in settings such as that of the current study, imagined contact may make intergroup differences and inequality more salient and thereby bolster collective action tendencies. 


\section{Acknowledgement}

We would like to thank XX UNIVERSITY for funding this research (Scientific Research Project Grant at XX University, BAP Grant No: 15B101). 


\section{References}

Allport, G. W. (1954). The nature of prejudice. Cambridge, MA: Addison-Wesley.

Asbrock, F., Gutenbrunner, L., \& Wagner, U. (2013). Unwilling, but not unaffected-Imagined contact effects for authoritarians and social dominators. European Journal of Social Psychology, 43, 404-412. DOI: 10.1002/ejsp.1956.

Bagci, S. C. \& Turnuklu, A. (in press). Intended, unintended, and unknown consequences of contact: The role of positive-negative contact on outgroup attitudes, collective action tendencies, and psychological well-being, Social Psychology, DOI: 10.1027/18649335/a000355.

Bagci, S. C., Stathi, S., \& Piyale, Z. E. (in press). Imagined contact facilitates acculturation, sometimes: Contradicting evidence from two different socio-cultural contexts. Cultural Diversity and Ethnic Minority Psychology, DOI: 10.1037/cdp0000256.

Bagci, S. C., \& Çelebi, E. (2017). Cross-group friendships and outgroup attitudes among Turkish-Kurdish ethnic groups: Does perceived interethnic conflict moderate the friendshipattitude link? Journal of Applied Social Psychology, 47, 59-73. DOI: 10.1111/jasp.12413.

Bagci, S. C., Piyale, Z. E., Bircek, N. I., \& Ebcim, E. (2017). Think beyond contact: Reformulating imagined intergroup contact theory by adding friendship potential. Group Processes \& Intergroup Relations, 21, 1034-1052. DOI: 10.1177/1368430217690237.

Bagci, S. C., Piyale, Z. E., \& Ebcim, E. (2018). Imagined contact in high conflict settings: The role of ethnic group identification and the perspective of minority group members. Journal of Applied Social Psychology, 48, 3-14. DOI: 10.1111/jasp.12485. 
Becker, J. C., Wright, S. C., Lubensky, M. E., \& Zhou, S. (2013). Friend or ally: Whether crossgroup contact undermines collective action depends on what advantaged group members say (or don't say). Personality and Social Psychology Bulletin, 39, 442-455. DOI: $10.1177 / 0146167213477155$.

Bilali, R., Çelik, A. B., \& Ok, E. (2014). Psychological asymmetry in minority-majority relations at different stages of ethnic conflict. International Journal of Intercultural Relations, 43, 253-264. DOI: 10.1016/j.ijintrel.2014.09.002.

Cameron, L., Rutland, A., Turner, R., Holman-Nicolas, R., \& Powell, C. (2011). "Changing attitudes with a little imagination": Imagined contact effects on young children's intergroup bias. Anales de Psicología, 27, 708-717.

Cakal, H., Hewstone, M., Schwär, G., \& Heath, A. (2011). An investigation of the social identity model of collective action and the 'sedative'effect of intergroup contact among Black and White students in South Africa. British Journal of Social Psychology, 50, 606-627. DOI: 10.1111/j.2044-8309.2011.02075.x.

Carvalho-Freitas, M. N. D., \& Stathi, S. (2017). Reducing workplace bias toward people with disabilities with the use of imagined contact. Journal of Applied Social Psychology, 47, 256266. DOI: $10.1111 /$ jasp. 12435.

Çakal, H., Hewstone, M., Güler, M., \& Heath, A. (2016). Predicting support for collective action in the conflict between Turks and Kurds: Perceived threats as a mediator of intergroup contact and social identity. Group Processes \& Intergroup Relations, 19, 732-752. DOI: $10.1177 / 1368430216641303$. 
Delcker, J. (2015, October 7). German anti-immigrant protests revive and radicalize: "Lying" media targeted in weekly protests centered on Dresden. Politico. Retrieved from http://www.politico.eu/article/german-anti-immigrant-protests-revive-and-radicalize.

Dixon, J., Durrheim, K., \& Tredoux, C. (2007). Intergroup contact and attitudes toward the principle and practice of racial equality. Psychological Science, 18, 867-872. DOI: 10.1111/j.1467-9280.2007.01993.x.

Dixon, J., Tropp, L. R., Durrheim, K., \& Tredoux, C. (2010). "Let them eat harmony": Prejudice-reduction strategies and attitudes of historically disadvantaged groups. Current Directions in Psychological Science, 19, 76-80. DOI: $10.1177 / 0963721410363366$.

Ellison, C. G., \& Powers, D. A. (1994). The contact hypothesis and racial attitudes among Black Americans. Social Science Quarterly, 75, 385-400.

Esses, V. M., Haddock, G., \& Zanna, M. P. (1993). Values, stereotypes, and emotions as determinants of intergroup attitudes. In Mackie, D., M. \& Hamilton, D., L. (Eds.) Affect, cognition and stereotyping: Interactive processes in group perception (pp. 137-166). San Diego: Academic Press.

Giacobbe, M. R., Stukas, A. A., \& Farhall, J. (2013). The effect of imagined versus actual contact with a person with a diagnosis of schizophrenia. Basic and Applied Social Psychology, 35, 265-271. DOI: 10.1080/01973533.2013.785403.

Göçek, F. M. (2011). The transformation of Turkey: Redefining state and society from the Ottoman Empire to the modern era (Vol. 103). IB Tauris. 
Harwood, J., Paolini, S., Joyce, N., Rubin, M., \& Arroyo, A. (2011). Secondary transfer effects from imagined contact: Group similarity affects the generalization gradient. British Journal of Social Psychology, 50, 180-189. DOI: 10.1348/014466610X524263. Hayes, A. F. (2013). Introduction to mediation, moderation, and conditional process analysis: A regression-based approach. New York: The Guilford Press.

Hodson, G., \& Hewstone, M. (Eds.). (2013). Advances in intergroup contact. New York, NY: Psychology Press.

Husnu, S., \& Crisp, R. J. (2010). Imagined intergroup contact: A new technique for encouraging greater inter-ethnic contact in Cyprus. Peace and Conflict: Journal of Peace Psychology, 16, 97-108. DOI: 10.1080/10781910903484776.

Kauff, M., Green, E. G. T., Schmid, K., Hewstone, M., \& Christ, O. (2016). Effects of majority members' positive intergroup contact on minority members' support for ingroup rights: Mobilizing or demobilizing effects? European Journal of Social Psychology, 46, 833-839. DOI:10.1002/ejsp.2194.

Konda (2011). Kürt Meselesinde Algl ve Beklentiler [Perceptions and Expectations in the Kurdish Issue]. Istanbul: Iletişim Yayınları.

Kuchenbrandt, D., Eyssel, F., \& Seidel, S. K. (2013). Cooperation makes it happen: Imagined intergroup cooperation enhances the positive effects of imagined contact. Group Processes and Intergroup Relations, 16, 635-647. DOI: 10.1177/1368430212470172.

Leach, C. W., Iyer, A., \& Pedersen, A. (2007). Angry opposition to government redress: When the structurally advantaged perceive themselves as relatively deprived. British Journal of Social Psychology, 46, 191-204. DOI: 10.1348/014466606X99360.

Liebkind, K., Mähönen, T. A., Solares, E., Solheim, E., \& Jasinskaja-Lahti, I. (2014). Prejudice- 
reduction in culturally mixed classrooms: The development and assessment of a theorydriven intervention among majority and minority youth in Finland. Journal of Community \& Applied Social Psychology, 24, 325-339. DOI: 10.1002/casp.2168.

Miles, E., \& Crisp, R. J. (2014). A meta-analytic test of the imagined contact hypothesis. Group Processes \& Intergroup Relations, 17, 3-26. DOI: 10.1177/1368430213510573.

Mutlu, S. (1996). Ethnic Kurds in Turkey: A demographic study. International Journal of Middle East Studies, 28, 517-541. DOI: 10.1017/S0020743800063819.

Norton, M. I., \& Sommers, S. R. (2011). Whites see racism as a zero-sum game that they are now losing. Perspectives on Psychological Science, 6, 215-218. DOI: $10.1177 / 1745691611406922$.

Pettigrew, T. F. (1998). Intergroup contact theory. Annual Review of Psychology, 49, 65-85. DOI: 10.1146/annurev.psych.49.1.65.

Pettigrew, T. F. (2009). Probing the complexity of intergroup prejudice. International Journal of Psychology, 44, 40-42. DOI: 10.1080/00207590802057936.

Pettigrew, T. F., \& Tropp, L. R. (2006). A meta-analytic test of intergroup contact theory. Journal of Personality and Social Psychology, 90, 751-783. DOI: 10.1037/0022-3514.90.5.751.

Pettigrew, T. F., \& Hewstone, M. (2017). The single factor fallacy: Implications of missing critical variables from an analysis of intergroup contact theory. Social Issues and Policy Review, 11, 8-37. DOI: 10.1111/sipr.12026.

Poore, A. G., Gagne, F., Barlow, K. M., Lydon, J. E., Taylor, D. M., \& Wright, S. C. (2002). Contact and the personal/group discrimination discrepancy in an Inuit community. The Journal of Psychology, 136, 371-382. DOI: 10.1080/00223980209604164. 
Reimer, N. K., Becker, J. C., Benz, A., Christ, O., Dhont, K., Klocke, U., Neji, S., Rychlowska, M., Schmid, K. \& Hewstone, M. (2017). Intergroup contact and social change: Implications of negative and positive contact for collective action in advantaged and disadvantaged groups. Personality and Social Psychology Bulletin, 43, 121-136. DOI: $10.1177 / 0146167216676478$.

Saab, R., Harb, C., \& Moughalian, C. (2017). Intergroup contact as a predictor of violent and nonviolent collective action: Evidence from Syrian refugees and Lebanese nationals. Peace and Conflict: Journal of Peace Psychology, 23, 297-306. DOI: 10.1037/pac0000234.

Saguy, T., \& Chernyak-Hai, L. (2012). Intergroup contact can undermine disadvantaged group members' attributions to discrimination. Journal of Experimental Social Psychology, 48, 714-720. DOI: 10.1016/j.jesp.2012.01.003.

Saguy, T., Shchory-Eyal, N., Hasan-Aslih, S., Sobol, D., \& Dovidio, J. F. (2017). The irony of harmony: Past and new developments. In Vezzali, L. \& Stathi, S. (Eds.) Intergroup contact theory: Recent developments and future directions (p. 53-71). Routledge: London.

Saguy, T., Tausch, N., Dovidio, J. F., \& Pratto, F. (2009). The irony of harmony: Intergroup contact can produce false expectations for equality. Psychological Science, 20, 114-121. DOI: 10.1111/j.1467-9280.2008.02261.x.

Schmitt, M. T., \& Branscombe, N. R. (2002). The meaning and consequences of perceived discrimination in disadvantaged and privileged social groups. European Review of Social Psychology, 12, 167-199. DOI: 10.1080/14792772143000058.

Stathi, S., \& Crisp, R. J. (2008). Imagining intergroup contact promotes projection to outgroups. Journal of Experimental Social Psychology, 44, 943-957. DOI: 10.1016/j.jesp.2008.02.003. 
Stathi, S., Crisp, R. J., \& Hogg, M. A. (2011). Imagining intergroup contact enables member-togroup generalization. Group Dynamics: Theory, Research, and Practice, 15, 275-284. DOI: 10.1037/a0023752.

Stathi, S., Tsantila, K., \& Crisp, R. J. (2012). Imagining intergroup contact can combat mental health stigma by reducing anxiety, avoidance and negative stereotyping. The Journal of Social Psychology, 152, 746-757. DOI: 10.1080/00224545.2012.697080.

Tausch, N., Saguy, T., \& Bryson, J. (2015). How does intergroup contact affect social change? Its impact on collective action and individual mobility intentions among members of a disadvantaged group. Journal of Social Issues, 71, 536-553. DOI: 10.1111/josi.12127.

Tropp, L. R., Hawi, D. R., Van Laar, C., \& Levin, S. (2012). Cross-ethnic friendships, perceived discrimination, and their effects on ethnic activism over time: A longitudinal investigation of three ethnic minority groups. British Journal of Social Psychology, 51, 257-272. DOI: 10.1111/j.2044-8309.2011.02050.x.

Tropp, L. R., Mazziotta, A., \& Wright, S. C. (2016). Recent developments in intergroup contact research: Affective processes, group status, and contact valence. In C. Sibley \& F. K. Barlow (Eds.), Cambridge handbook of the psychology of prejudice (pp. 463-480). Cambridge, UK: Cambridge University Press.

Tropp, L. R., \& Pettigrew, T. F. (2005). Relationships between intergroup contact and prejudice among minority and majority status groups. Psychological Science, 16, 951-957. DOI: 10.1111/j.1467-9280.2005.01643.x.

Turner, R. N., \& Crisp, R. J. (2010). Imagining intergroup contact reduces implicit prejudice. British Journal of Social Psychology, 49, 129-142. DOI: 10.1348/014466609X419901. 
Turner, R. N., Crisp, R. J., \& Lambert, E. (2007). Imagining intergroup contact can improve intergroup attitudes. Group Processes \& Intergroup Relations, 10, 427-441. DOI: $10.1177 / 1368430207081533$.

Uluğ, Ö. M., \& Cohrs, J. C. (2017). "If we become friends, maybe I can change my perspective:" Intergroup contact, endorsement of conflict narratives, and peace-related attitudes in Turkey. Peace and Conflict: Journal of Peace Psychology, 23, 278-287

Van Zomeren, M., \& Iyer, A. (2009). Introduction to the social and psychological dynamics of collective action. Journal of Social Issues, 65, 645-660. DOI: 10.1111/j.15404560.2009.01618.x.

Van Zomeren, M., Postmes, T., \& Spears, R. (2008). Toward an integrative social identity model of collective action: a quantitative research synthesis of three socio-psychological perspectives. Psychological Bulletin, 134, 504-535. DOI: 10.1037/0033-2909.134.4.504.

Van Zomeren, M., Spears, R., Fischer, A. H., \& Leach, C. W. (2004). Put your money where your mouth is! Explaining collective action tendencies through group-based anger and group efficacy. Journal of Personality and Social Psychology, 87, 649-664. DOI:

10.1037/0022-3514.87.5.649.

Verkuyten, M., \& Martinovic, B. (2006). Understanding multicultural attitudes: The role of group status, identification, friendships, and justifying ideologies. International Journal of Intercultural Relations, 30, 1-18. DOI: 10.1016/j.ijintrel.2005.05.015.

Verkuyten, M., \& Yildiz, A. A. (2006). The endorsement of minority rights: The role of group position, national context, and ideological beliefs. Political Psychology, 27, 527-548. DOI: 10.1111/j.1467-9221.2006.00525.x. 
Verkuyten, M., Thijs, J., \& Bekhuis, H. (2010). Intergroup contact and ingroup reappraisal: Examining the deprovincialization thesis. Social Psychology Quarterly, 73, 398-416. DOI: $10.1177 / 0190272510389015$.

Vezzali, L., Capozza, D., Giovannini, D., \& Stathi, S. (2012). Improving implicit and explicit intergroup attitudes using imagined contact: An experimental intervention with elementary school children. Group Processes \& Intergroup Relations, 15, 203-212. DOI: $10.1177 / 1368430211424920$.

Vezzali, L., Capozza, D., Stathi, S., \& Giovannini, D. (2012). Increasing outgroup trust, reducing infrahumanization, and enhancing future contact intentions via imagined intergroup contact. Journal of Experimental Social Psychology, 48, 437-440. DOI: 10.1016/j.jesp.2011.09.008.

Vezzali, L., Hewstone, M., Capozza, D., Giovannini, D., \& Wölfer, R. (2014). Improving intergroup relations with extended and vicarious forms of indirect contact. European Review of Social Psychology, 25, 314-389. DOI: 10.1080/10463283.2014.982948.

Vezzali, L., Saguy, T., Andrighetto, L., Giovannini, D., \& Capozza, D. (2016). When direct contact is not enough: Extended contact and desire for equality. Under review.

West, K., \& Bruckmüller, S. (2013). Nice and easy does it: How perceptual fluency moderates the effectiveness of imagined contact. Journal of Experimental Social Psychology, 49, 254262. DOI: 10.1016/j.jesp.2012.11.007.

West, K., \& Greenland, K. (2016). Beware of "reducing prejudice": Imagined contact may backfire if applied with a prevention focus. Journal of Applied Social Psychology, 46, 583592. DOI: $10.1111 /$ jasp.12387. 
West, K., Holmes, E., \& Hewstone, M. (2011). Enhancing imagined contact to reduce prejudice against people with schizophrenia. Group Processes \& Intergroup Relations, 14, 407-428.

West, K., Turner, R. N., \& Levita, L. (2015). Applying imagined contact to improve physiological responses in anticipation of intergroup interactions and the perceived quality of these interactions. Journal of Applied Social Psychology, 45, 425-436. DOI: $10.1111 /$ jasp.12309.

Wright, S. C., \& Lubensky, M. (2009). The struggle for social equality: Collective action vs. prejudice reduction. In S. Demoulin, J. P. Leyens \& J. F. Dovidio (Eds.), Intergroup misunderstandings: Impact of divergent social realities. New York: Psychology Press.

Yetkili, O., Abrams, D., Travaglino, G. A., \& Giner-Sorolla, R. (2018). Imagined contact with atypical outgroup members that are antinormative within their group can reduce prejudice. Journal of Experimental Social Psychology, 76, 208-219

https://dx.doi.org/10.1016/j.jesp.2018.02.004. 